University of Nebraska - Lincoln

DigitalCommons@University of Nebraska - Lincoln

Michigan Bovine Tuberculosis Bibliography and

Database

Wildlife Disease and Zoonotics

2002

\title{
Milk Containing Mycobacterium bovis as a Source of Infection for White-Tailed Deer Fawns (Odocoileus virginianus)
}

\author{
M. V. Palmer \\ Bacterial Diseases of Livestock Research Unit,National Animal Disease Center,Agricultural Research \\ Service,USDA,Ames, IA, Mitchell.Palmer@ars.usda.gov \\ W. R. Waters \\ Bacterial Diseases of Livestock Research Unit,National Animal Disease Center,Agricultural Research \\ Service,USDA,Ames, IA \\ D. L. Whipple \\ Bacterial Diseases of Livestock Research Unit,National Animal Disease Center,Agricultural Research \\ Service,USDA,Ames, IA
}

Follow this and additional works at: https://digitalcommons.unl.edu/michbovinetb

Part of the Veterinary Medicine Commons

Palmer, M. V.; Waters, W. R.; and Whipple, D. L., "Milk Containing Mycobacterium bovis as a Source of Infection for White-Tailed Deer Fawns (Odocoileus virginianus)" (2002). Michigan Bovine Tuberculosis Bibliography and Database. 76.

https://digitalcommons.unl.edu/michbovinetb/76

This Article is brought to you for free and open access by the Wildlife Disease and Zoonotics at DigitalCommons@University of Nebraska - Lincoln. It has been accepted for inclusion in Michigan Bovine Tuberculosis Bibliography and Database by an authorized administrator of DigitalCommons@University of Nebraska Lincoln. 


\title{
Milk containing Mycobacterium bovis as a source of infection for white-tailed deer fawns (Odocoileus virginianus)
}

\author{
M. V. Palmer, W. R. Waters, D. L. Whipple \\ Bacterial Diseases of Livestock Research Unit, National Animal Disease Center, Agricultural Research Service, USDA, Ames, IA, USA
}

Summary Setting: White-tailed deer represent the first wildlife reservoir of Mycobacterium bovis in the United States. The behavior of does with nursing fawns provides several potential mechanisms for disease transmission. Little information exists concerning transmission between doe and fawn, specifically transmammary transmission.

Objective: Determine if fawns can become infected by ingestion of milk replacer containing M. bovis, thus simulating transmission from doe to fawn through contaminated milk.

Design: Seventeen, 21-day-old white-tailed deer fawns were inoculated orally with $2 \times 10^{8} \mathrm{CFU}$ (high dose, $n=5$ ), $2.5 \times 10^{5}$ to $2.5 \times 10^{6} \mathrm{CFU}$ (medium dose, $n=5$ ), and $1 \times 10^{4} \mathrm{CFU}$ (low dose, $n=5$ ) of $M$. bovis in milk replacer. Dosages were divided equally and fed daily over a 5-day period. Positive control fawns $(n=2)$ received $1 \times 10^{5} \mathrm{CFU}$ of $M$. bovis instilled in the tonsillar crypts. Fawns were euthanized and examined 35-115 days after inoculation and various tissues collected for bacteriologic and microscopic analysis.

Results: All fawns in the tonsillar, high oral and medium oral dose groups developed generalized tuberculosis involving numerous organs and tissues by 35-84 days after inoculation. Three of five fawns in the low-dose oral group had tuberculous lesions in the mandibular lymph node, and one of five had lesions in the medial retropharyngeal lymph node when examined 115 days after inoculation.

Conclusion: White-tailed deer fawns can become infected through oral exposure to M. bovis. Therefore, the potential exists for fawns to acquire M. bovis while nursing tuberculous does. @ Published by Elsevier Science Ltd.

\section{INTRODUCTION}

In 1994 a free-ranging white-tailed deer (Odocoileus virginianus) in Michigan was diagnosed with tuberculosis due to Mycobacterium bovis. ${ }^{1}$ Subsequent surveys conducted by the Michigan Department of Natural Resources and Michigan State University Animal Health Diagnostic Laboratory identified a focus of $M$. bovis infection in freeranging white-tailed deer in northeast Michigan. ${ }^{1,2}$ This represents the first known wildlife reservoir of $M$. bovis in the United States and the first known focus of tuberculosis in white-tailed deer in the world. Several factors are thought to have contributed to the establishment and persistence of $M$. bovis in this wildlife reservoir. These

Correspondence to: Mitchell V. Palmer, DVM, PhD, Bacterial Diseases of Livestock Research Unit, National Animal Disease Center, Agricultural Research Service, USDA, 2300 Dayton Avenue, Ames, IA 50010, USA. Tel.: +1-515-663-7474; fax: +1-515-663-7458;

e-mail:mpalmer@nadc.ars.usda.gov factors include, the large number of cattle infected with M. bovis in Michigan during the late 1950s, ${ }^{3}$ and a deer population that has steadily grown beyond normal habitat carrying capacity to focal concentrations of 1923 deer $/ \mathrm{km}^{2}{ }^{1}{ }^{1}$ A contributing factor to deer overpopulation has been long-term winter feeding to prevent migration and decrease winter mortality in order to keep deer numbers high for hunting purposes. ${ }^{1}$ Winter feeding not only results in increased numbers of deer, but causes prolonged crowding of deer around feeding sites with increased opportunity for deer-to-deer contact and enhanced transmission of tuberculosis.

Previously, it has been shown that deer housed in close contact may directly and indirectly transmit $M$. bovis to uninfected penmates; ${ }^{4}$ however, little is known concerning doe to fawn transmission of tuberculosis. Between doe and fawn, the possibility of in utero or transmammary transmission exists in addition to transmission through close contact. This study was conducted to examine the susceptibility of white-tailed deer fawns to 
M. bovis infection after consumption of milk replacer containing $M$. bovis, thus simulating transmammary transmission.

\section{MATERIALS AND METHODS}

\section{Animals}

White-tailed deer ( $n=17$; neonatal, male and female) were removed from their dams $24-36 \mathrm{~h}$ after birth. Deer were part of a research herd at the National Animal Disease Center (NADC) in Ames, IA, USA. Fawns were fed a milk replacer (Kid Milk Replacer, Purina Mills, St Louis, MO, USA) for 21 days according to a standard white-tailed deer fawn feeding regimen. Deer were housed according to dosage group in facilities approved by the International Association for the Assessment of Laboratory Animal Care (IAALAC). A protocol detailing all procedures to be conducted was approved by the Institutional Animal Care and Use Committee at the NADC prior to the experiment.

\section{Inoculation}

At 21 days of age, fawns were moved to a biosecurity level 3 (BL-3) animal housing facility and randomly assigned to one of four groups. The high-dose group $(n=5)$ received $4 \times 10^{7}$ CFU $M$. bovis daily for 5 days. The medium-dose group $(n=5)$ received $5 \times 10^{4}$ to $5 \times 10^{5} \mathrm{CFU}$ of $M$. bovis daily for 5 days and the low-dose group $(n=5)$ received $2 \times 10^{3} \mathrm{CFU}$ of $M$. bovis daily for 5 days. To insure complete consumption of the inoculum, all deer received the inoculum in $60 \mathrm{ml}$ of milk replacer for 5 consecutive days. Immediately after consuming the challenge inoculum, fawns were fed the remainder of the milk replacer for a single feeding (approximately $450-600 \mathrm{ml}$ ). Total doses, therefore, were $2 \times 10^{8}, 2.5 \times 10^{5}$ to $2.5 \times 10^{6}$, and $1 \times 10^{4} \mathrm{CFU}$ for the high-, medium-, and low-dose groups, respectively. Positive control fawns $(n=2)$ received $1 \times 10^{5} \mathrm{CFU}$ of $M$. bovis 1315 instilled in the tonsillar crypts under anesthesia as previously described. ${ }^{5}$ M. bovis strain 1315 , originally isolated from a white-tailed deer in Michigan was used for all inoculations.

\section{Necropsy and sample collection}

The original experimental protocol called for necropsy of all groups 115 days after inoculation. However, 39 days after inoculation, one fawn from the high-dose group was euthanized by intravenous sodium pentobarbital, due to advanced tuberculosis. The remaining four fawns from the high-dose group were euthanized and examined 50 days after inoculation. For similar humane concerns, one fawn from the medium-dose group was euthanized and examined on each of days 35 and 60 after inoculation.
The remaining three fawns from the medium-dose group and the two positive control fawns were euthanized and examined 84 days after inoculation. Fawns from the lowdose group were euthanized and examined 115 days after inoculation.

At necropsy, the following tissues or fluids were collected and processed for isolation of $M$. bovis as described previously; ${ }^{5}$ palatine tonsil, lung, liver, mandibular, parotid, medial retropharyngeal, tracheobronchial, mediastinal, hepatic, and mesenteric lymph nodes, feces, and swabs of the nasal and oral cavity. Isolates were identified as $M$. bovis by colony and biochemical characteristics as well as a DNA probe specific for mycobacteria in the M. tuberculosis complex (AccuProbe; Gen-Probe Inc., San Diego, CA, USA). Tissues collected for microscopic analysis included all tissues collected for bacteriologic examination, as well as other tissues with gross lesions resembling tuberculosis, and were fixed by immersion in 10\% neutral buffered formalin, processed by routine methods to paraffin wax and sectioned $(5 \mu \mathrm{m})$. Sections were stained with hematoxylin and eosin (H/E) for microscopic examination. Adjacent sections were cut from samples containing lesions suggestive of tuberculosis and stained by the Ziehl-Neelsen technique for identification of acid-fast bacteria. ${ }^{6}$

\section{RESULTS}

Fawns dosed through intratonsilar inoculation of M. bovis developed disseminated tuberculosis involving tonsils, cranial, thoracic and mesenteric lymph nodes, lung, liver and kidney. One fawn also had lesions in the spleen and pancreas. Likewise, all fawns in the high- and mediumdose groups developed disseminated tuberculosis with granulomatous lesions in cranial, thoracic, and mesenteric lymph nodes and the lung, liver, kidney, spleen and pancreas (Fig. 1); additionally, lesions were seen in both

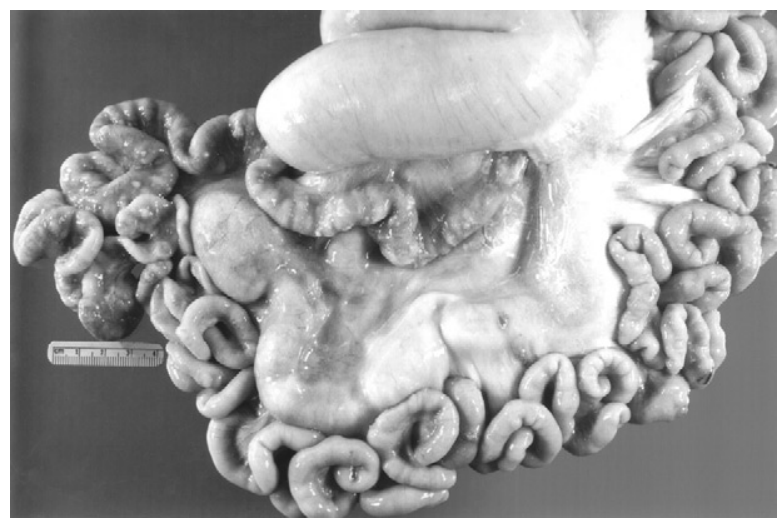

Fig. 1 Small and large intestines from a white-tailed deer fawn orally inoculated with $2 \times 10^{8} \mathrm{CFU} M$. bovis (high-dose group) and euthanized 50 days later. Note the chain of enlarged mesenteric lymph nodes. 
the small and large intestine (Fig. 2). No gross or microscopic lesions were seen in fawns receiving the lowest dose of $M$. bovis (Table 1).

Microscopically, lesions in all tissues were characterized by multifocal to coalescent granulomas composed of accumulations of epithelioid macrophages, Langhan'stype multinucleated giant cells and lymphocytes surrounding central cores of caseous necrosis (Fig. 3). Within both the small and large intestine, there was marked expansion of the mucosa and submucosa due to multifocal to coalescent caseonecrotic granulomas (Fig. 4). Multifocally, there was erosion to ulceration of mucosa overlying expansive submucosal granulomas.

Isolation of $M$. bovis from tissue samples correlated well with the presence of lesions (Table 1). Additionally,

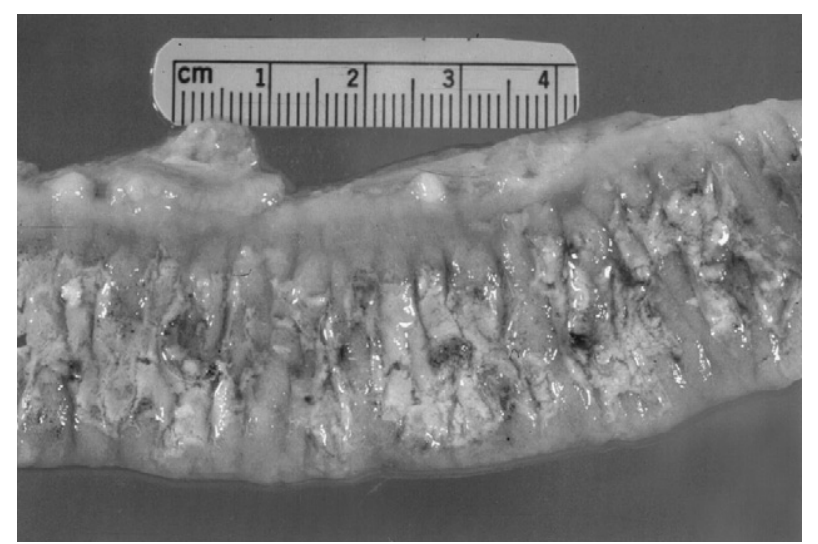

Fig. 2 Section of ileum from a white-tailed deer fawn orally inoculated with $2 \times 10^{8}$ CFU M. bovis (high-dose group) and euthanized 50 days later. Note the thickened corrugated appearance of the mucosa and multifocal ulcerative lesions covered by a fibrinonecrotic membrane. however, $M$. bovis was isolated from the mandibular and medial retropharyngeal lymph nodes in three and one of five fawns, respectively, in the low-dose group. M. bovis was isolated from nasal swabs collected at necropsy from four of five fawns in the high-dose group and one of five fawns in each of the medium- and low-dose groups. Isolation of $M$. bovis was also made from the oral swab of one of five deer in the medium-dose group. Swabs of the oral cavity from both intratonsilar inoculated fawns, as well the nasal swab from one of the two fawns, contained M. bovis.

\section{DISCUSSION}

The present study demonstrates that white-tailed deer fawns can develop tuberculous lesions following ingestion of M. bovis; therefore, shedding of $M$. bovis from the mammary gland of the dam could serve as an important means of deer-to-deer transmission. However, tuberculous lesions of the mammary gland of white-tailed deer have been reported only rarely. ${ }^{2}$ Furthermore, the magnitude of shedding of $M$. bovis in milk from naturally infected white-tailed deer is not known. Extrapolation from cattle studies suggests that large numbers of bacilli may be present in milk from tuberculous cows. Although excretion of bacilli is highly variable and often intermittent, numbers of bacilli may exceed one million $/ \mathrm{ml}{ }^{7}$ Moreover, it has been shown that excretion of $M$. bovis in milk can occur in tuberculous cows in the absence of mammary gland lesions. ${ }^{7}$ Therefore, the paucity of mammary gland lesions in white-tailed deer examined to date, does not preclude the possibility of excretion of $M$. bovis through milk from tuberculous deer.

Table 1 Summary of lesions and bacteriologic culture results of white-tailed deer fawns fed various dosages of $M$. bovis in milk replacer.

\begin{tabular}{|c|c|c|c|c|c|c|c|c|c|c|c|c|}
\hline \multirow[b]{3}{*}{ Tissue } & \multicolumn{12}{|c|}{ Group } \\
\hline & \multicolumn{3}{|c|}{ High dose } & \multicolumn{3}{|c|}{ Medium dose } & \multicolumn{3}{|c|}{ Low dose } & \multicolumn{3}{|c|}{ Intratonsillar } \\
\hline & $\mathrm{G}$ & $\mathrm{M}$ & $\mathrm{B}$ & $\mathrm{G}$ & $\mathrm{M}$ & $\mathrm{B}$ & $\mathrm{G}$ & $\mathrm{M}$ & $\mathrm{B}$ & $\mathrm{G}$ & $\mathrm{M}$ & $B$ \\
\hline Tonsil & $0 / 5$ & $4 / 5$ & $5 / 5$ & $3 / 5$ & $3 / 5$ & $3 / 5$ & $0 / 5$ & $0 / 5$ & $0 / 5$ & $2 / 2$ & $2 / 2$ & $1 / 2$ \\
\hline Mandibular LN & $1 / 5$ & $5 / 5$ & $4 / 5$ & $3 / 5$ & $3 / 5$ & $3 / 5$ & $0 / 5$ & $0 / 5$ & $3 / 5$ & $2 / 2$ & $2 / 2$ & $2 / 2$ \\
\hline Parotid LN & $2 / 5$ & $5 / 5$ & $5 / 5$ & $1 / 5$ & $2 / 5$ & $4 / 5$ & $0 / 5$ & $0 / 5$ & $0 / 5$ & $1 / 2$ & $1 / 2$ & $2 / 2$ \\
\hline Med retropharyngeal LN & $4 / 5$ & $5 / 5$ & $5 / 5$ & $5 / 5$ & $5 / 5$ & $4 / 5$ & $0 / 5$ & $0 / 5$ & $1 / 5$ & $2 / 2$ & $2 / 2$ & $2 / 2$ \\
\hline Tracheobronchial LN & $5 / 5$ & $5 / 5$ & $5 / 5$ & $5 / 5$ & $5 / 5$ & $3 / 5$ & $0 / 5$ & $0 / 5$ & $0 / 5$ & $2 / 2$ & $2 / 2$ & $1 / 2$ \\
\hline Mediastinal LN & $5 / 5$ & $4 / 5$ & $5 / 5$ & $4 / 5$ & $5 / 5$ & $4 / 5$ & $0 / 5$ & $0 / 5$ & $0 / 5$ & $2 / 2$ & $2 / 2$ & $2 / 2$ \\
\hline Lung & $5 / 5$ & $5 / 5$ & $4 / 5$ & $5 / 5$ & $5 / 5$ & $4 / 5$ & $0 / 5$ & $0 / 5$ & $0 / 5$ & $2 / 2$ & $2 / 2$ & $2 / 2$ \\
\hline Liver & $5 / 5$ & $5 / 5$ & $4 / 5$ & $5 / 5$ & $5 / 5$ & $3 / 5$ & $0 / 5$ & $0 / 5$ & $0 / 5$ & $2 / 2$ & $2 / 2$ & $2 / 2$ \\
\hline Hepatic LN & $5 / 5$ & $5 / 5$ & $5 / 5$ & $5 / 5$ & $5 / 5$ & $4 / 5$ & $0 / 5$ & $0 / 5$ & $0 / 5$ & $2 / 2$ & $2 / 2$ & $2 / 2$ \\
\hline Mesenteric LN & $5 / 5$ & $5 / 5$ & $5 / 5$ & $5 / 5$ & $5 / 5$ & $4 / 5$ & $0 / 5$ & $0 / 5$ & $0 / 5$ & $2 / 2$ & $2 / 2$ & $2 / 2$ \\
\hline Kidney* & $5 / 5$ & $4 / 5$ & & $4 / 5$ & $3 / 5$ & & $0 / 5$ & $0 / 5$ & & $2 / 2$ & $1 / 2$ & \\
\hline Small intestine ${ }^{*}$ & $5 / 5$ & $5 / 5$ & & $4 / 5$ & $4 / 5$ & & $0 / 5$ & $0 / 5$ & & $0 / 2$ & $0 / 2$ & \\
\hline Large intestine ${ }^{*}$ & $5 / 5$ & $5 / 5$ & & $4 / 5$ & $4 / 5$ & & $0 / 5$ & $0 / 5$ & & $0 / 2$ & $0 / 2$ & \\
\hline Spleen ${ }^{*}$ & $3 / 5$ & $3 / 5$ & & $3 / 5$ & $4 / 5$ & & $0 / 5$ & $0 / 5$ & & $0 / 2$ & $1 / 2$ & \\
\hline Pancreas ${ }^{*}$ & & & & & $2 / 5$ & & $0 / 5$ & $0 / 5$ & & $0 / 2$ & $1 / 2$ & \\
\hline
\end{tabular}

$\mathrm{LN}=$ lymph node, $\mathrm{G}=$ gross lesion, $\mathrm{M}=$ microscopic lesion, $\mathrm{B}=$ isolation of $M$. bovis. Not collected from all animals and not processed for bacteriologic isolation of $M$. bovis. 


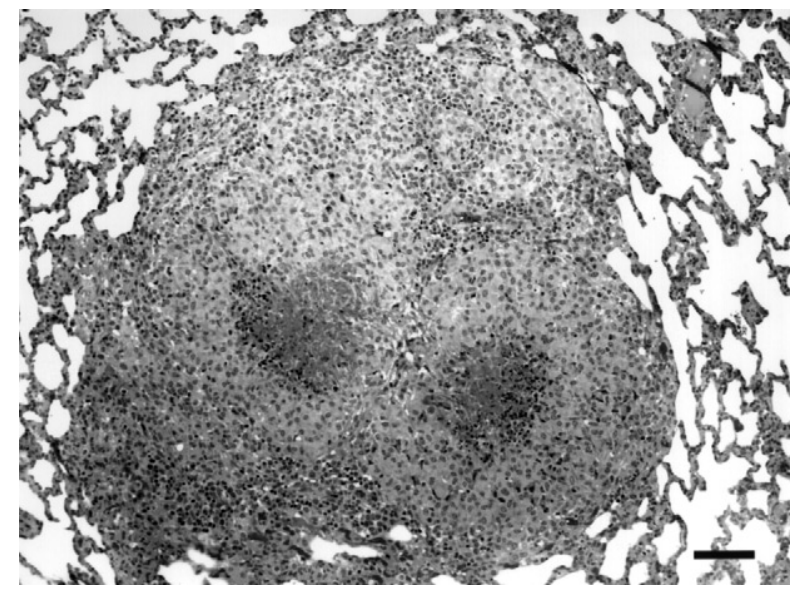

Fig. 3 Photomicrograph of a section of lung from a white-tailed deer fawn orally inoculated with $2 \times 10^{8} \mathrm{CFU} M$. bovis (high-dose group) and euthanized 50 days later. Note the coalescent granulomas composed of epitheliod macrophages, multinucleated giant cells and lymphocytes surrounding a caseonecrotic core. H/E. Bar $=88 \mu \mathrm{m}$.

Prior to the present study, the relative susceptibility of white-tailed deer fawns to infection through the oral route was unknown. It has been shown in guinea-pigs, cattle and sheep that infection through the oral route requires $16-18$ million times more bacilli than infection through the respiratory route. ${ }^{7}$ Oral inoculation of sheep with $1.3 \times 10^{7}$ bacilli failed to establish infection in all animals. ${ }^{8}$ Likewise in humans ingesting milk from $M$. bovis infected cows, greater that $10^{3}$ bacilli $/ \mathrm{ml}$ must be present for infection to occur. ${ }^{9}$ Based on these previous reports, the white-tailed deer fawns in the present study were inoculated with dosages of $M$. bovis similar to those used in other studies of oral inoculation. Furthermore, the severity of the resulting disease in fawns demonstrates the high susceptibility of this species to infection with $M$. bovis. Finally, as fawns were housed according to treatment group, the potential for fawn-tofawn transmission within groups cannot be excluded. Transmission of $M$. bovis between experimentally infected white-tailed deer in close contact has been reported previously. ${ }^{4}$

The impact of oral inoculation on white-tailed deer fawns in nature is unclear. Disease surveys thus far have failed to detect significant tuberculosis in fawns. However, these surveys have relied on hunter-killed deer of which young deer $(<1$ year age) are poorly represented. ${ }^{1,2}$ Reports of young white-tailed and red deer (Cervus elaphus) fawns likely to have been infected during the neonatal period are infrequent. ${ }^{10,11}$ One report described M. bovis infection in elk (Cervus elaphus), moose (Alces alces), and mule deer (Odocoileus hemionus) fawns, the source of which was thought to be infected bovine milk. ${ }^{12}$ A report cited by Clifton-Hadley (1991) suggests

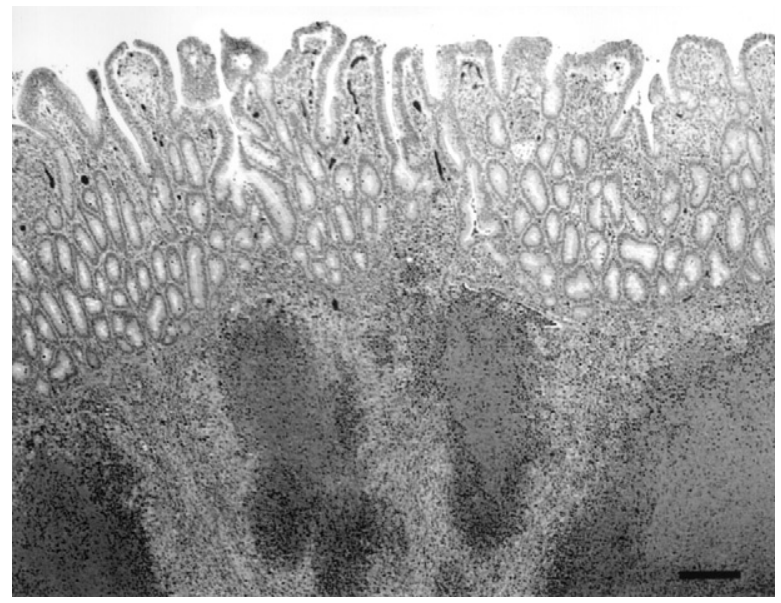

Fig. 4 Photomicrograph of a section of ileum from a white-tailed deer fawn orally inoculated with $2 \times 10^{8}$ CFU M. bovis (high-dose group) and euthanized 50 days later. Note the marked expansion of the submucosa by multifocal caseonecrotic granulomas. $\mathrm{H} / \mathrm{E} . \mathrm{Bar}=140 \mu \mathrm{m}$.

that fawns may be more susceptible to infection and acute disease than are adults. ${ }^{13}$ However, several other reports document the increased prevalence of tuberculosis in older deer, rather than nursing or recently weaned fawns. ${ }^{1,10,14,15}$

Milk has long been considered a primary means of transmission of $M$. bovis from cattle to man. Nevertheless, it is estimated that only about $1 \%$ of tuberculous cattle have mammary gland lesions. ${ }^{16,17}$ In spite of this low prevalence of mammary gland lesions, offspring from tuberculous ruminants are at increased risk of contracting tuberculosis, presumably from consumption of milk containing M. bovis. ${ }^{18,19}$ Lesions involving the mesenteric lymph nodes are common in cattle allowed to nurse from tuberculous udders or milk from tuberculous cows, however; lesions of the alimentary mucosa, as seen in the current study, are uncommon in cattle. ${ }^{20}$ Likewise lesions involving the pancreas are also uncommon in cattle. ${ }^{20}$ The development of such lesions in the present study may be related to dosage of inoculum, source of inoculum, or host species differences.

White-tailed deer are the most numerous free-ranging ruminant in North America. Tuberculosis in this population represents a serious threat to the US livestock industry as well as a potential public health concern. Clearly, more insight is needed in understanding the susceptibility of white-tailed deer fawns to M. bovis as well as excretion of $M$. bovis in milk from tuberculous white-tailed deer. Understanding the mechanisms of transmission will provide useful information in the development of strategies to control or eradicate this important animal and zoonotic disease. 


\section{ACKNOWLEDGEMENTS}

The authors thank Rebecca Lyon, Jody Mentele, Theresa Rahner and Lori Dethloff for technical assistance and Wayne Varland, Doug Ewing, Norm Lyon, Clarissa Hoff, Nathan Meyer, Dan Altena, Joseph Eggers and Breanne Marpe for animal care.

\section{REFERENCES}

1. Schmitt S M, Fitzgerald S D, Cooley T M et al. Bovine tuberculosis in free-ranging white-tailed deer from Michigan. J Wild Dis 1997; 33: 749-758.

2. O'Brien D J, Fitzgerald S D, Lyon T J et al. Tuberculous lesions in free-ranging white-tailed deer in Michigan. J Wild Dis 2001; 37: 608-613.

3. Frye G H. Bovine tuberculosis eradication: the program in the United States. In: Thoen C O, Steele J H, eds. Mycobacterium bovis infection in animals and humans. Ames, IA: Iowa State University Press, 1995: pp 119-129.

4. Palmer M V, Whipple D L, Waters R W. Experimental deer to deer transmission of Mycobacterium bovis. Am J Vet Res 2001; 62: 692-696.

5. Palmer M V, Whipple D L, Olsen S C. Development of a model of natural infection with Mycobacterium bovis in white-tailed deer. J Wild Dis 1999; 35: 450-457.

6. Sheehan D C, Hrapchak B B. (Eds) Microorganisms. In: Theory and practice of histotechnology, 2nd edn. St Louis: Mosby Publishing, 1980: pp 233-251.

7. Sigurdson J. Studies on the risk of infection with bovine tuberculosis to the rural population. Acta Tuberculosea scandinavica supplementum XV. Copenhagen: Munskgaard, 1945: pp 26-40.

8. Francis J. Bovine tuberculosis, including a contrast with human tuberculosis. New York: Staples Press Limited, 1947: pp 86-87.
9. Francis J. Control of infection with the bovine tubercle bacillus. Lancet 1950; 258: 34-39.

10. Lugton I W, Wilson P R, Morris R S, Nugent G. 1998. Epidemiology and pathogenesis of Mycobacterium bovis infection of red deer (Cervus elaphus) in New Zealand. NZ Vet J 1998; 46: 147-156.

11. Palmer M V, Whipple D L, Payeur J B, Alt D P, Esch K J, Bruning-Fann C S, Kaneene J B. Naturally occurring tuberculosis in white-tailed deer. J Am Vet Med Assoc 2000; 216: 1921-1924.

12. Hawden S. Tuberculosis in the buffalo. J Am Vet Med Assoc 1942 100: $19-22$

13. Clifton-Hadley R S, Wilesmith J W. Tuberculosis in deer: a review. Vet Rec 1991; 129: 5-12.

14. Stuart F A. Tuberculosis in farmed red deer (Cervus elaphus). In: Reid HW, ed. Management and health of farmed deer. Dordecht, Netherlands: Kluwer Academic Publishers, 1988: pp 101-111.

15. Paterson K. Management of tuberculosis in a fallow deer herd. Surveillance 1993; 20: 27-28.

16. Stamp J T. Tuberculosis of the bovine udder. J Comp Pathol Therap 1943; 53: 220-230.

17. Grange J M, Yates M D. Zoonotic aspects of Mycobacterium bovis infection. Vet Microbiol 1994; 40: 137-151.

18. Soliman K N, Rollinson D H L, Barron N S, Spratling F R. An outbreak of naturally acquired tuberculosis in goats. Vet Rec 1953; 65: 421-424.

19. Evangelista T B R, Hernandez de Anta J. Tuberculosis in dairy calves: risk of Mycobacterium spp. Exposure associated with management of colostrum and milk. Prev Vet Med 1996; 27: 23-27.

20. Dungworth D L. The respiratory system. In: Jubb K V F, Kennedy P C, Palmer N, eds. Pathology of the domestic animals, 4th edn. San Diego: Academic Press, 1993: pp 539-699. 